\title{
Relato de experiência das atividades desenvolvidas no Subprojeto Interdisciplinar- PIBID/UERR 2014.1 a 2015.1
}

\author{
Rosilda da Rocha Veloso ${ }^{1}$ \\ 1. Universidade Estadual de Roraima. Rua 7 de Setembro, 231, Canarinho. Boa Vista/RR. CEP: 69306-530. \\ E-mail para contato: rochaveloso4@gmail.com
}

Recebido em : 12 de outubro de 2015. Aceito em: 26/12/2015.

\begin{abstract}
RESUMO
Relato de experiência das atividades desenvolvidas no Subprojeto Interdisciplinar- PIBID/UERR 2014.1 a 2015.1. O intento deste relato de experiência é ressaltar a importância da interação entre a educação superior e a educação da rede básica de ensino para o aperfeiçoamento da formação acadêmica, mediante abordagem da importância das práticas desenvolvidas pelos licenciandos à sua formação docente, bem como, o incentivo no aprendizado dos alunos da Educação Básica. Impacto percebido na aceitação e dedicação na qual os alunos executaram as atividades propostas pelos acadêmicos. Interação que se fez possível pela oportunidade trazida com a implantação do Programa Institucional de Bolsa de Iniciação à Docência PIBID/UERR. Esta parceria que tem proporcionado oportunidades de desenvolvimento pessoal e intelectual tanto de alunos, quanto de professores efetivos e graduandos nos diversos níveis do sistema de ensino através do incentivo e valorização do magistério. O Programa Institucional possibilita o aprofundamento necessário, para fomentar o amadurecimento das discussões sobre o ensino referente ao embasamento teórico e epistemológico sobre a função do docente. Sabemos que um professor não é somente um transmissor de conteúdos, ele exerce função política importante na formação do profissional e do sujeito em sala de aula, o que vem sendo aperfeiçoado com a inserção de acadêmicos futuros professores da rede pública de ensino ao ambiente escolar, para que desenvolvam atividades didáticopedagógicas especialmente na sala de aula, fatores esses, que tem proporcionado a concretização de diversas atividades propostas pelo subprojeto interdisciplinar, mediante reuniões de planejamento, orientações, acompanhamento e avaliação das atividades.
\end{abstract}

PALAVRAS CHAVE: Interdisciplinaridade, Política, Políticas Públicas.

\begin{abstract}
Experience report of the activities developed in Subproject Interdisciplinary- PIBID / 2014.1 and 2015.1 UERR. The purpose of this experience report is to highlight the importance of interaction between higher education and education in the basic education system for the improvement of academic training by approach of the importance of practices developed by licensees to your teacher training, as well as the encouragement learning of basic education students. Perceived impact acceptance and dedication in which students performed the activities proposed by academics. Interaction that is made possible by the opportunity brought with the implementation of the Institutional Program Initiation Grant to Teaching PIBID/UERR. This partnership has provided opportunities to weigh-sonal and intellectual development of both students, as effective teachers and graduate students at various levels of the education system by encouraging and enhancement of teaching. The Institutional Program provides the necessary deepening, to promote the ripening of discussions about teaching regarding the theoretical and epistemological foundations on the role of teacher. We know that a teacher is not only a content transmitter, it plays an important political role in the formation of professional and subject in the classroom, which has been enhanced with the inclusion of future academic teachers of public schools in the school environment, to develop didactic and pedagogical activities especially in the classroom, these factors, which has provided the implementation of several activities proposed by the interdisciplinary subproject through planning meetings, guidance, monitoring and evaluation of activities.
\end{abstract}

KEY WORDS: Interdisciplinary, Politics, Public Policy.

\section{INTRODUÇÃO}

O presente trabalho tem por finalidade apresentar relato de experiência das atividades desenvolvidas no Subprojeto Interdisciplinar "Política e Políticas Públicas" do Programa Institucional de Bolsa de Iniciação à Docência PIBID/UERR 2014.1 a 2015.1. O Programa Institucional de Bolsa de Iniciação à Docência (PIBID) é uma ação conjunta do Ministério da Educação, por intermédio da Secretaria de
Educação Superior -(SESu), da Fundação Coordenação de Aperfeiçoamento de Pessoal de Nível Superior-(CAPES) e do Fundo Nacional de Desenvolvimento da Educação-(FNDE), com vistas a fomentar a iniciação à docência de estudantes das Instituições Públicas de Ensino Superior-(IPES) e preparar a formação de docentes em cursos de licenciatura plena, presencial, para atuar na educação básica pública. 
O programa PIBID é desenvolvido por instituições de Educação superior (IES) em parceria com Escolas de Educação Básica da Rede Pública de Ensino. Oferece bolsas de iniciação à docência aos estudantes de cursos de licenciatura que desenvolvam atividades pedagógicas em escolas da rede pública de educação básica; ao coordenador institucional que articula e implementa o programa na universidade; aos coordenadores de área envolvidos na orientação aos bolsistas; e, ainda, aos docentes de escolas públicas responsáveis pela supervisão dos licenciandos. Também são repassados recursos de custeio para execução de atividades vinculadas ao projeto.

A implementação do Subprojeto PIBID/ INTERDISCIPLINAR, se deu com o intuito de ampliar o conhecimento dos acadêmicos bolsistas das disciplinas de Filosofia, Geografia, História e Sociologia a partir da compreensão das múltiplas causas ou fatores que intervêm sobre a realidade. $O$ que possibilitou trabalhar as linguagens necessárias para a constituição de conhecimentos e a tomada de resultados, a partir da necessidade sentida pelas escolas, professores e alunos.

A realização deste perfil de trabalho é de extrema importância para a comunidade científica, para o ensino e para a formação destes alunos envolvidos. Uma vez que, incentiva a escolha pela carreira docente por meio da valorização do magistério; promove a integração entre a educação superior e a educação da rede básica de ensino; articula os saberes teóricos e práticos, mediante inserção direta dos acadêmicos no cotidiano escolar proporcionando a eles, experiências que envolvam o uso de metodologias, planejamentos e recursos alternativos que efetivam a prática docente; bem como, incentiva as instituições de nível superior à pesquisa e as ações acadêmicas voltadas à formação de professores.

A classificação dos acadêmicos bolsistas para o Projeto Interdisciplinar PIBID/UERR, se deu mediante seleção, tendo como requisito uma carta de intenção, média acadêmica e disponibilidade para atuação em horário oposto as aulas na Universidade Estadual de Roraima, não podendo comprometer a carga horária curricular obrigatória dos cursos de graduação. Portanto, este trabalho foi sistematizado em cumprimento às propostas do PIBID/UERR, em parceria com as Escolas da Rede Pública de Ensino.

\section{MATERIAL E MÉTODOS}

As atividades do PIBID/UERR foram desenvolvidas mediante inserção direta dos acadêmicos bolsistas no ambiente escolar, tendo como campo de atuação especialmente a sala de aula, o que não excluiu a realização de atividades extraclasses. As ações pedagógicas durante os semestres de 2014.1 a 2015.1 buscaram o diagnóstico da interdisciplinaridade e do tratamento do tema "política e políticas públicas" dentro da Escola Estadual Gonçalves Dias, situada à Avenida Getúlio Vargas, ${ }^{\circ}$ 4333, Bairro Canarinho, no município de Boa Vista - Roraima. A instituição é mantida pela Secretaria de Educação, Cultura e Desporto do Estado de Roraima, foi criada pelo decreto $\mathrm{n}^{\circ}$ 12, de 24 de março de 1977, e reconhecida pelo Parecer $n^{\circ} 54 / 80$ do então Conselho Territorial de Educação. Sua denominação homenageia o poeta lírico Antônio Gonçalves Dias, natural da cidade de Caxias - Maranhão, considerado um dos maiores representantes do Romantismo no contexto da literatura nacional.

Esta parceria tem proporcionado oportunidades de desenvolvimento pessoal e intelectual tanto de alunos, quanto de professores efetivos e graduandos nos diversos níveis do sistema de ensino através do incentivo e valorização do magistério.

As atividades e critérios adotados foram escolhidos em sua maioria pelos coordenadores de área envolvidos na orientação aos bolsistas em conjunto com o supervisor (docente da disciplina de História na escola campo), ouvidas sempre as sugestões dos acadêmicos bolsistas. Partindo das discussões, foram repassadas pelos coordenadores todas as informações precisas a cerca das atividades exigidas; a pontuação a ser atribuída a cada uma delas e os prazos para realização, ficando assim, os acadêmicos bolsistas sujeitos ao desligamento do programa caso fossem confirmados o não cumprimento dentro dos prazos estabelecidos, ressalvado apresentações de justificativas válidas. Em conformidade com as exigências do Subprojeto, foram disponibilizados os modelos de plano de ensino, plano de aula, modelo de resumo, além dos recursos metodológicos e materiais pedagógicos para a realização das atividades.

A execução das tarefas se deu no primeiro momento com a leitura do Projeto Político 
Pedagógico-(PPP) da escola campo, investigado a existência da interdisciplinaridade e do tema de "política e/ ou políticas públicas" contidas no (PPP) da escola, produziu-se um relatório descritivo sobre os temas em questão. Cada bolsista se dedicou 2 horas semanais para esta atividade, o controle da mesma foi feito através da qualidade do relatório.

Fez-se a leitura dos livros didáticos de Geografia, História e Filosofia onde investigou a existência de conteúdos relacionados ao tema do subprojeto "Política e/ou Políticas públicas" com base nas investigações, produziu-se 3 (três) Planos de Ensino, sendo um de cada disciplina específica, 1 (um) Plano de aula da disciplina de História, 4(quatro) aulas experimentais, sendo duas da disciplina de Geografia e duas da disciplina de Filosofia e por ultimo, 1(uma) miniaula da disciplina de História. Cada bolsista se dedicou 2 horas semanais para estas atividades, o controle das mesmas foi feito através da qualidade das atividades, observadas às exigências propostas.

Durante a execução do projeto os bolsistas supervisionados pelo docente da disciplina de História na escola campo dedicaram 1 hora/aula por semana para observar os conteúdos ministrados em sala de aula, tentando perceber a didática empregada, assim como a relação que os conteúdos ministrados tinham com os temas do subprojeto (Política e Políticas Públicas). Nesses encontros, após as observações, os bolsistas recebiam orientações para a prática docente, assim como tomavam ciência de atividades a serem desenvolvidas na sala de aula ou extraclasse. O controle de frequência era feito pelo Professor-Supervisor, que repassava as assinaturas dos bolsistas, mensalmente, aos coordenadores do subprojeto.

Como produto das observações foi entregue aos Coordenadores um portfólio detalhando os conteúdos ministrados pelo professor supervisor, a relação com os temas do subprojeto, a metodologia empregada pelo professor, bem como o uso de materiais didáticos e modos de exposição do conteúdo.

Tendo em vista a necessidade dos bolsistas em serem assessorados nas atividades propostas, assim como a instrumentalização dos mesmos na temática de "Teoria política e políticas públicas" além das reuniões que eram realizadas quinzenalmente com a coordenação do subprojeto, desenvolveram-se grupos de estudos, os encontros eram feitos mensalmente para discussão.

Tiveram como fundamentação teórica as obras: Estado, governo e mercado, do autor: Ricardo Corrêa Coelho (2009) e Políticas Públicas da autora: Maria das Graças Rua (2012). Os bolsistas dedicaram-se 4 horas mensais, para esta atividade. Como produto das discussões, foi desenvolvido 1 (um) resumo de (500 a 1000 caracteres) sobre a origem e estrutura organizacional do modelo de Estado Socialista, com base nas obras estudadas.

No Evento Institucional do PIBID, evento ocorrido duas vezes a cada ano, os bolsistas ministraram um minicurso com a temática: Políticas Públicas implantadas no Brasil para sediar a Copa do Mundo em 2014, esta atividade ocorreu em Alto Alegre, Município de Boa Vista-RR.

Com o intuito de fomentar a discursão a respeito do uso de recursos imagéticos em sala de aula, como tratar a imagem (seja ela feita através de fotos, gravuras, vídeos, filmes, teatro, etc.) de modo crítico e como usá-la como recurso metodológico, sem que ela seja vista como reprodução ideológica, a coordenação do Subprojeto Interdisciplinar PIBID/UERR, ofertou uma oficina e/ou minicurso para a Capacitação e Formação Continuada dos professores de Filosofia, Sociologia, História e Geografia das escolas envolvidas no subprojeto. A participação dos bolsistas no minicurso acima citado se deu de maneira obrigatória, tomaram como base os conhecimentos adquiridos no minicurso, e nesta ação, separados em 4 grupos. Cada grupo sob orientação do seu respectivo supervisor apresentou e discutiu trechos de filmes e vídeos que retratavam uma perspectiva de política e de ações políticas em prol da construção da sociedade.

Foi entregue aos coordenadores, no ato da apresentação, um plano da respectiva aula. E por último, em grupos, foram apresentadas a importância das disciplinas de Geografia, História e Sociologia para o avanço da sociedade.

$\mathrm{O}$ andamento das atividades propostas pelo subprojeto interdisciplinar se deu mediante seguimento de um cronograma de reuniões de planejamento, orientações, acompanhamentos e avaliações das atividades, organizadas mediante pesquisas bibliográficas, estudos em grupos e fundamentações teóricas. 


\section{RESULTADOS E DISCUSSÃO}

A inserção direta ao ambiente escolar público ocorreu dia 28 de março de 2014 na Escola Estadual Gonçalves Dias, atualmente a escola conta com aproximadamente 880 (oitocentos e oitenta) alunos matriculados nas modalidades de Ensino Médio Regular e Integrado ao Profissional, distribuídos em 29 (vinte e nove) turmas, que funcionam em dois turnos (matutino e vespertino).

Resgatar a identidade e a função social da escola são alguns dos objetivos da Gestão Escolar que tem sido alcançado com um trabalho voltado para a gestão democrática e participativa, desenvolvendo projetos como: a Gincana Cultural, Copa GD, a Profissão dos Meus Sonhos, Arraial Cultural, Feira do Conhecimento, Igarapé Curupira - Preservar para não acabar, Aluno Solidário, Adolescência e Sexualidade, Combatendo as Tensões para Melhorar a Qualidade de Vida, Simulado GD, Olimpíada de Matemática do GD, Saúde e Prevenção, Projeto Água Potável, OPAM (O Prazer de Aprender Matemática), Projeto Aluno Monitor, entre outros.

Dessa forma, a Gestão tem se atentado ao processo de mudança no contexto social e nos avanços tecnológicos para que a Escola possa desenvolver e praticar os princípios da estética da sensibilidade em suas ações, os pressupostos da política, da igualdade e os princípios pedagógicos de interdisciplinaridade, diversidade e contextualização, buscando assim, desenvolver competências necessárias para projeto de vida como pessoa humana, incluir o pensamento crítico e a autonomia intelectual, oferecendo ao aluno orientação básica para a sua integração no mundo do trabalho.

Com base nas informações contidas no Projeto Político Pedagógico (PPP), a Escola Estadual Gonçalves Dias busca uma escola autônoma, democrática, que assegure a qualidade da aprendizagem, envolvendo toda comunidade escolar, para que participem como sujeitos no processo educativo.

Para garantir a realização desses objetivos, a Escola Estadual Gonçalves Dias desenvolve projetos e ações voltadas para as necessidades da clientela com metodologias diferenciadas, e incentiva a capacitação dos docentes para auxiliar nas transformações da educação desejada e almejada por todos.

Em cumprimento a proposta de incentivo, a
Escola Estadual Gonçalves Dias fez parceria com o Programa Institucional de bolsa de Iniciação a Docência (PIBID/UERR), uma política pública, voltada para a garantia dos direitos sociais, configurando assim, um compromisso público. Ou seja, no momento em que a escola abriu as portas para que os acadêmicos vivenciassem a realidade de uma sala de aula, concomitantemente além da valorização e experiência, a escola ofertou um incentivo para o aperfeiçoamento da formação acadêmica.

As atividades foram desenvolvidas na sala de aula e extraclasse. Durante a execução do projeto, os bolsistas ministraram aulas expositivas, entregaram relatórios das atividades desenvolvidas, resumos das obras estudadas; planos de ensino; planos de aula; portfólio; e relatório do Projeto Político Pedagógico (PPP) da escola campo.

Os livros de História, Geografia e Filosofia foram investigados procurando conteúdos relacionados ao tema do Subprojeto: Política e/ ou Políticas Públicas, ministrou-se um minicurso sobre as Políticas Públicas implantadas no Brasil para sediar a Copa do Mundo em 2014.

Foram desenvolvidos estudos sobre a obra: Estado, governo e mercado, do autor: Ricardo Corrêa Coelho (2009) e Políticas Públicas da autora: Maria das Graças Rua (2012).

Houve discussões sobre o ensino e atividades nas escolas, produção e execução de oficinas; planejamento; seleção e desenvolvimento de atividades extraclasses, a exemplo, a realização de um passeio turístico em que retratou a origem da cidade de Boa Vista-RR, e as políticas públicas adotadas para restauração e conservação dos patrimônios públicos.

Fez-se uma exposição de uma sala climática, com objetivo de promover uma sensibilização da comunidade geral e acadêmica para as transformações ocorridas nos diferentes tipos de climas devido à intervenção do homem na natureza.

Organizado pela Coordenação, os bolsistas participaram de um minicurso com o tema "O uso da imagem em sala de aula": a oferta teve o intuito de fomentar a discussão a respeito do uso de recursos imagéticos em sala de aula, como tratar a imagem (seja ela feita através de fotos, gravuras, vídeos, filmes, teatro, etc.) de modo crítico e como usá-la como recurso metodológico, sem que ela seja vista como 
reprodução ideológica.

Com base no minicurso acima citado, em grupo, foi montado um documentário com a temática - Bullying: As políticas públicas desenvolvidas no Estado de Roraima para prevenção e combate dessa prática dentro do ambiente escolar. Foi montado a partir de gravações de entrevistas realizadas pelos acadêmicos bolsistas no Centro de Boa VistaRR, salientando pronunciamentos de experiências vivenciadas, onde a prática de Bullying deixou traumas nas vítimas, algumas conseguiram se superar, enquanto que outros ainda lutam contra essas "cicatrizes" que ficaram enraizadas. Fez-se definição do termo Bullying e os diferentes tipos existentes, tendo como base o pensamento de Fante (2011) autora do livro Fenômeno bullying: como prevenir a violência nas escolas e educar para a paz.

Para ilustração utilizou-se imagens retiradas da internet retratando tal prática e recorte do filme Bang Bang - você morreu, o filme retrata a história da vida de Trevor, um estudante problemático que luta pra se libertar do constante bullying que sofre na escola, retrata um professor de teatro e vídeo tentando encenar a peça em um ambiente semelhante ao que é seu foco. Neste filme vemos problemas como falta de diálogo, incompreensão, hostilidade, hipocrisia e tantos outros típicos de intolerância.

Com a finalidade de promover a ciência da existência de políticas públicas desenvolvidas no Estado de Roraima para prevenção e combate de tal prática, citou-se a existência da Lei $\mathrm{n}^{\circ} 894$ de 25 de janeiro de 2013, dispõe sobre a instalação de câmeras de segurança nas Escolas Públicas do Estado de Roraima; do Projeto de Lei Autorizativo $\mathrm{n}^{\circ}$ 017, de 2011, que autoriza o Poder Executivo Estadual a criar o Programa Estadual de Combate ao Bullying nas escolas públicas e privadas do Estado de Roraima e a Lei ${ }^{\circ} 1.342$ de Junho de 2011, que autoriza a Prefeitura de Boa Vista-RR criar o Programa de Combate ao Bullying, de ação interdisciplinar e de participação comunitária, nas escolas públicas e privadas do município.

Com o intuito de levar a discussão para sala de aula, utilizou-se esse documentário e ministrou-se uma palestra na escola campo.

E por último, apresentou-se ao coordenador do Subprojeto Interdisciplinar uma aula expositiva sobre a importância da disciplina de história para o avanço da sociedade.
As aulas em sua maioria foram ministradas na sala de aula da escola campo, onde o Supervisor responsável pelo acompanhamento, avaliação e controle das frequências se fazia presente durante toda a exposição, outras para $o$ coordenador e acadêmicos bolsistas, ministradas na sala da coordenação do Subprojeto, localizada na própria Universidade, e as aulas de campo, ou seja, extraclasses, estas últimas, envolveram os alunos da Rede Pública, o Supervisor (docente da disciplina de História na escola campo) e Coordenadores do Subprojeto. As ministrações em campo ocorreram sempre nas horas-aulas do Professor -Supervisor e teve o intuito de buscar sistematicamente e registrar os resultados dos conteúdos discutidos em sala de aula.

Todas as programações, os conteúdos a serem ministrados, e datas para apresentações foram acompanhadas pelo ProfessorSupervisor incumbido de avaliar as fontes, biografias e planejamento das atividades, bem como diagnosticar se havia necessidade de auxilio teórico. Esses procedimentos eram feitos dias antes da apresentação, ocorriam em reuniões semanalmente, na escola campo.

Dependendo dos recursos necessários para a realização das atividades na classe, a exemplo a utilização de Microfone, Caixa de som, Datashow, e de um espaço mais amplo, inclusive, autorizados pelo Professor e Gestor escolar, os alunos se deslocavam da sala de aula para o auditório parte integrante da instituição, prática que se repetia quando se tratava de ministrações de palestras, dinâmicas, exposição de documentários, entre outros.

Os objetivos propostos pelo programa foram alcançados de maneira satisfatória, a concretização das atividades se deu pela aceitação e credibilidade no PIBID, valores atribuídos pelos Coordenadores do Subprojeto; Supervisor, Corpo Administrativo e alunos da escola campo. Sabe-se que não basta somente a oportunidade de inserção no ambiente escolar, mas, para que os acadêmicos aperfeiçoassem suas formações se fez necessária à condição de acesso e permanência, e, os agentes da escola campo em geral juntamente com os coordenadores e supervisores do Subprojeto foram parte significativa na articulação das propostas, contribuindo assim, para o alcance desse sucesso.

Para cada objetivo a ser alcançado fez-se necessário à seleção de conteúdos e métodos em função desses objetivos; condição 
organizativa para se estabelecer os vínculos entre o ensino e aprendizagem, tendo em vista o desenvolvimento das capacidades mentais dos alunos. As impressões dos licenciandos ao realizá-las foram de superação, pois conseguiram desenvolver as atividades satisfatoriamente, conforme o planejado com os professores supervisores e coordenadores.

A cada produção se percebeu a importância do planejamento que segundo Libâneo (1994)

É um processo de racionalização, organização e coordenação da ação docente, articulando a atividade escolar e a problemática do contexto social [...] a ação de planejar, portanto, não se reduz ao simples preenchimento de formulários para controle administrativo; é antes a atividade consciente de previsão das ações docentes, fundamentadas em opções político- pedagógicas, e tendo como referência permanente as situações didáticas concretas (isto é, a problemática social, econômica, política e cultural que envolve a escola, os professores, os alunos, os pais, a comunidade, que integram no processo de ensino) (Libâneo, 1994, p. 222).

Durante as reuniões com os licenciandos, contemplou-se um amadurecimento significativo, a luz das teorias estudadas, o que culminou no aperfeiçoamento da formação acadêmica. A cada atividade exigida, tornavase um desafio que era superado ao se apresentar como resultado uma produção científica. As reações e impressões dos acadêmicos na preparação das atividades demostraram um compromisso com a educação, e acima de tudo com a qualificação profissional, pois se acredita que só se pode ter uma educação de qualidade, que assegure ao aluno da Educação Básica o pleno desenvolvimento da cidadania e a qualificação para o trabalho, se houver professores qualificados e compromissados com o ensino-aprendizagem.

Atividades essas, que tem permitido por meio da experiência, perceber que a prática educativa como disse Zabala (1998): "é algo fluído, fugidio, difícil de limitar com coordenadas simples, é complexa, devida nela se expressarem múltiplos fatores como: ideias, valores, hábitos pedagógicos, etc. Podendo ser interpretada mediante as relações interativas; a organização social da aula; o tempo e o espaço; a organização dos conteúdos; os materiais curriculares e os recursos didáticos e a avaliação". Posto isso, percebe-se que trata de um processo, na qual para se consumar, depende da correlação de diferentes ações.

Por ser o subprojeto de caráter interdisciplinar, tem permitido ampliar a visão de mundo, enriquecer as pesquisas, além da construção de saberes com informações e procedimentos de diferentes campos do conhecimento, partindo da compreensão das múltiplas causas ou fatores que intervêm sobre a realidade, o que possibilitou trabalhar as linguagens necessárias para a constituição de conhecimentos e a tomada de resultados, partindo da necessidade sentida pelas escolas, professores e alunos.

Fazenda (2008), afirma que a interdisciplinaridade atravessa fronteiras disciplinares e pode integrar saberes, quando seus princípios forem praticados.

Sobre os princípios da interdisciplinaridade, Fazenda é referenciada por Godoy (2011) em sua Tese de Doutorado em Educação para esclarecer o que significa cada um desses princípios:

Coerência entre o que pensamos e o que fazemos; respeito por si próprio e pelo outro, por ele ser diferente; humildade em reconhecer que construímos um mundo e não o mundo com o outro; espera que significa observar todos os fenômenos que pudermos capturar no tempo e no espaço e desapego, tanto de bens intelectuais quanto de bens materiais, significa estar aberto a novas ideias. Salienta Fazenda que o exercício desses princípios deve ser desenvolvido pelo olhar e pela escuta sensível. (Fazenda apud Godoy, 2011, p.69).

Fazenda (2008) define a interdisciplinaridade como sendo:

Uma nova atitude diante da questão do conhecimento, de abertura à compreensão de aspectos ocultos do ato de aprender e dos aparentemente expressos, colocando-os em questão. Exige, portanto, na prática, uma profunda imersão no trabalho cotidiano. Não se aprende a interdisciplinaridade somente com teorias sem sua práxis, o que torna o processo flexível, de conhecimentos e de ajustes constantes, e se respeita os lugares de onde se fala e onde se esteve, onde as experiências acumuladas não são ignoradas e sim acrescentadas, e algo novo é construído sem desrespeito ao antigo. (Fazenda, 2008, p.119).

Ou seja, considera que o que se pretende com a interdisciplinaridade não é a eliminação da contribuição de cada disciplina, mas a 
criação de condições de ensinar-se em função das relações dinâmicas entre as diferentes disciplinas, aliando-se aos problemas da sociedade. Propõe, portanto um tecer coletivo de saberes e olhares, mediado pelo diálogo, única condição possível de eliminação das barreiras entre as disciplinas.

Em conformidade com os escritos de Fazenda, diante das instabilidades que as instituições têm passado nos últimos dias, para Ferreira e Dias:

(...) entre os desafios da Universidade está o de problematizar o seguinte paradoxo: não se pode reformar a Instituição se anteriormente as mentes não forem reformadas; mas só se pode reformar as mentes se a instituição for previamente reformada. Quem educará os educadores? Nesse sentido, há que se pensar no movimento de passagem do paradigma disciplinar ao interdisciplinar, no entanto, sem suprimir as disciplinas, mas articulá-las, religá -las, dar-lhes vitalidade e fecundidade para articular teoria e prática. (Ferreira \& Dias, 2010, p. 5)

Assim, a interdisciplinaridade vem como aspiração emergente em prol a superação da racionalidade científica positivista, quebrando paradigmas e propondo a visão de um todo, como afirma os escritos nos Parâmetros Curriculares Nacionais - Ensino Médio (2002). "A interdisciplinaridade tem uma função instrumental, trata-se de recorrer a um saber diretamente útil e utilizável para resolver às questões e aos problemas sociais contemporâneos".

Desta forma, acredita-se que a interdisciplinaridade pode facilitar a inserção de processos complexos no ambiente acadêmico, integrando sujeitos, aproximando disciplinas e permeando temas de forma a acelerar trocas de aprendizados e saberes.

É com essa perspectiva que a Universidade Estadual de Roraima tem contribuído para o avanço do ensino-aprendizagem, mediante a implementação do Programa Institucional de Bolsa de Iniciação a Docência (PIBID/UERR), visto ter acatado a emergente teoria da interdisciplinaridade, e buscado o desenvolvimento diante da complexidade do fenômeno educativo, abandonando olhares disciplinares e avançando no sentido de repensar fatos, dimensões e processo educacional de maneira a buscar soluções mais adequadas, em contraste com inadequações profundas e graves, como afirma Morin et al. (2009), "entre saberes em disjunção, em pedaços, compartimentalizados entre disciplinas e desarticulados da realidade e os problemas que são cada vez mais multidisciplinares, e globais".

Ressalto ainda, ser de extrema importância as reuniões de planejamento, orientações, acompanhamento e avaliação das atividades realizadas pelo professor-supervisor e coordenadores de área envolvidos na orientação aos bolsistas do Subprojeto Interdisciplinar, o que tem culminado na elevação dos conceitos e desempenhos das atividades nas escolas públicas da rede básica de ensino, alcançando assim, as metas do PIBID/UERR, mediante o aperfeiçoamento e valorização da formação de professores para a educação básica.

Sobre a formação profissional de professores, Libâneo (1994) afirma, "É um processo pedagógico, intencional e organizado, de preparação teórico-científica ${ }^{1}$ e técnica do professor para dirigir competentemente o processo de ensino".

Posto isso, a formação profissional do professor implica, pois, uma contínua interpenetração entre a teoria e prática, que segundo o autor a teoria está vinculada aos problemas reais postos pela experiência prática e a ação prática orientada teoricamente, permitindo assim, uma maior segurança profissional, de modo que o docente ganhe base para pensar sua prática e aprimore sempre mais a qualidade do seu trabalho.

Interpenetração entre teoria e prática que foi trazida com a implementação do Programa Institucional de Bolsa de Iniciação a Docência na qual possibilitou $\mathrm{o}$ aprofundamento necessário, para fomentar o amadurecimento

1. A formação de professor abrange, pois, duas dimensões: a formação teórico-cientifica, incluindo a formação acadêmica específica nas disciplinas em que o docente vai especializar-se e a formação pedagógica que envolve os conhecimentos da Filosofia, Sociologia, História da Educação e da Própria Pedagogia que contribuem para o esclarecimento do fenômeno educativo no contexto histórico-social; e a formação técnico-prática visando à preparação profissional específica para a docência, incluindo a Didática, as metodologias específicas das matérias, a Psicologia da Educação, a pesquisa educacional e outras. 
das discussões sobre o ensino referente ao embasamento teórico e epistemológico sobre a função do docente.

Por ser o subprojeto de caráter interdisciplinar, melhorou significativamente a formação inicial docente, primeiramente pelo conhecimento ter recuperado sua totalidade e complexidade; ou seja, o conjunto desses estudos tem permitido aos futuros professores e professores efetivos uma compreensão global do fenômeno educativo, especialmente de suas manifestações no âmbito escolar, o que tem despertado a necessidade de repensarem as suas práticas docentes; já os alunos tem adquirido um aprendizado significativo devido o ensino ser voltado para compreensão do mundo que os cercam; sem suprimir as disciplinas, mas articulando-as, e por ultimo, a escola tem avançado por ter sua proposta pedagógica refletida a todo instante, pensando criticamente os problemas e desafios postos pela realidade social, aumentando assim sua capacidade de atuação, o que consequentemente reflete no alcance dos objetivos educacionais almejado pela rede pública de ensino.

\section{AGRADECIMENTOS}

A CAPES pelo financiamento, e todas as instituições parceiras pela a oportunidade que conduziu a realização das atividades propostas. Agradeço também ao Professor-Supervisor e aos Coordenadores do Subprojeto, pelas orientações, e avaliações, que contribuíram significativamente para o aperfeiçoamento e preparação da formação docente.

\section{REFERÊNCIAS BIBLIOGRÁFICAS}

Brasil. Ministério da Educação. Secretaria de Educação Média e Tecnológica. 2002. Parâmetros Curriculares Nacionais: Ensino Médio. Brasília: Ministério da Educação.

Capes. Coordenação de Aperfeiçoamento de Pessoal de Nível Superior. 2015. Programa Institucional de Bolsa de Iniciação à Docência - PIBID. (http:// capes.gov.br/ educacao-basica/capespibid). Acesso em: 11/08/2015.

Coelho, R. C. 2009. Estado, governo e mercado. Florianópolis: Departamento de Ciências da Administração /UFSC; (Brasília): CAPES:UAB. $116 \mathrm{p}$.
Fante, C. 2011. Fenômeno bullying: como prevenir a violência nas escolas e educar para a paz. $6^{\mathrm{a}} \mathrm{ed}$. Campinas, SP: Verus Editora. 224p.

Fazenda, I. C. A. (Org.). 2008. O que é a Interdisciplinaridade? São Paulo: Cortez. 199p.

Ferreira, N. \& Dias, J.G. 2010. Prática pedagógica interdisciplinar e docência no ensino superior. Centro Universitário de Belo Horizonte. Belo Horizonte: UNIBH/ANIMA, (http://www.PUCSPsp.br/gepi/). Acesso em: 10 mai. 2015.

Godoy, H. P. 2011. A consciência espiritual na educação Interdisciplinar. São Paulo. Tese (Doutorado em Educação: Currículo) - Pontifícia Universidade Católica de São Paulo.

Libâneo, J.C. 1994. Didática. São Paulo: Cortez. 263p.

Morin, E., Ciurnana, E.R. \& Motta, R.D. 2009. Educar na era planetária: o pensamento complexo como método de aprendizagem no erro e na incerteza humana. 3. ed. São Paulo: Cortez. 112p.

Rua, M. G. 2012. Politicas públicas. 2. ed. Florianópolis: Departamento de Ciências da Administração /UFSC, 2012. 128 p.

Zabala, A. 1998. A prática educativa: como ensinar. Porto Alegre: ArtMed. 224p 